\title{
Source-Sink Relationship and Protea Postharvest Leaf Blackening
}

\author{
Jingwei Dai' and Robert E. Paull \\ Department of Plant Molecular Physiology, University of Hawaii at Manoa, Honolulu, HI 96822
}

Additional index words. Protea neriifolia, cut flower, nectar production, radioactivity

\begin{abstract}
The inflorescence of Protea neriifolia B. Br. was two-thirds of the total cut floral stem fresh weight and significantly influenced blackening of the attached 20 to 30 leaves. Floral stems harvested at five developmental stages were characterized for inflorescence diameter, fresh and dry weights, respiration, and nectar production. Inflorescence diameter and fresh and dry weights increased from stage 1 (very tight bud) to stage 5 (bracts reflexed). Respiration rate was high in stages 1 and 3 . Nectar production began at stage 4 (open, cylindrical flower) and increased from 2.7 to $9.8 \mathrm{ml}$ per flower with $15 \%$ to $23.5 \%$ total soluble solids as the flower opened. Postharvest inflorescence diameter, respiration rate, and nectar production increased and leaf blackening decreased when floral stems were placed in 5\% (w/v) sucrose solution. Application of ${ }^{14} \mathrm{C}$-sucrose to a leaf subtending the inflorescence lead to $>50 \%$ of the radioactivity being found in the nectar within 24 hours. These data indicate that leaf blackening in protea is the result of depletion of carbohydrate by the inflorescence, and that this depletion is primarily due to the sugar demand for nectar production.
\end{abstract}

The inflorescence of Protea neriifolia (13 cm long, 6-8 cm in diameter) has an involucral receptacle $(5-6 \mathrm{~cm}$ in diameter) with 300-400 individual florets surrounded by three to five layers of involucral bracts (Rourke, 1980). Commercially, the floral stem is harvested when the inner bracts are beginning to unfold. The postharvest life of the inflorescence can be as long as 3-4 weeks. However, postharvest leaf blackening significantly reduces the vase life to $\approx 1$ week (Bieleski et al., 1992; McConchie et al., 1991), greatly reducing the flower's market value.

Removal of the inflorescence significantly delays the onset of the leaf blackening (Dai, 1993; Paull et al., 1980; Reid et al., 1989). The inflorescence continues to expand after harvest and exhibits a high rate of respiration (Ferreira, 1986) with a large volume of nectar production when open (Cowling and Mitchell, 198 1). Therefore, the flower is a significant sink for carbohydrates. Removing the inflorescence, girdling the stem just below the in florescence (Dai, 1993; Reid et al., 1989), adding 2.5\% to 5\% (w/ v) of sugar to the vase solution (Dai, 1993), or placing floral stems in a bright light condition (Reid et al., 1989) delays or even prevents leaf blackening. Bieleski et al. (1992) and McConchie et al. (199 1) found that starch and sucrose concentration in leaves declined under postharvest conditions when flower stems were held in the dark but increased in the light.

These data suggest that postharvest inflorescence development and associated nectar production are major sinks for carbohydrate and that depleting carbohydrate from the leaves and the floral stem leads to leaf blackening. While research has been done analyzing the carbohydrate profile of Protea neriifolia leaves (McConchie et al., 1991; McConchie and Lang, 1993) and studying the influence of the inflorescence on leaf blackening (Reid et al., 1989), there is no study on the influence of postharvest inflorescence development on leaf blackening. There is also no direct evidence concern-

Received for publication 24 Mar. 1994. Accepted for publication 17 Nov. 1994. Hawaii Institute of Tropical Agriculture and Human Resources Journal Series. We express our appreciation for the plant material provided by Roy Tanaka, farm manager of Maui Branch Station, Univ. of Hawaii. Mention of a trade mark or proprietary product does not constitute a guarantee or warranty of a product by the University of Hawaii and does not imply its approval to the exclusion of other products that may also be suitable. The cost of publishing this paper was defrayed in part by the payment of page charges. Under postal regulations, this paper therefore must be hereby marked advertisement solely to indicate this fact.

'Junior researcher.

${ }^{2}$ Plant physiologist. ing source-sink relationships and which part of the inflorescence has the strongest sink demand. Our hypothesis was that carbohydrate demand, from flower development, flower opening, and nectar production, causes leaf blackening. Therefore, in this study, in florescence growth and nectar production are studied to determine the relationship between inflorescence development and leaf blackening. Movement of carbohydrates from leaf to the inflorescence was determined by applying ${ }^{14} \mathrm{C}$-sucrose to the leaf to study the source-sink relation and relative sink strength.

\section{Materials and Methods}

Plant material. Protea neriifolia 'Pink Mink' cut floral stems were provided by the Univ. of Hawaii Experimental Station, Kula, Maui. Stems with flowers at different stages of opening were harvested in the morning, packed in cardboard boxes without a plastic wrap, and air shipped to Honolulu the same day. After arrival, the cut flowers were immediately unpacked and trimmed to $45 \mathrm{~cm}$ long with 25 leaves per stem, then grouped into five developmental stages based on degree of opening with characteristic inflorescence diameter and fresh and dry weights (Table 1). The basal stem was recut $(2 \mathrm{~cm})$ and placed into a flask containing 1 liter of deionized water or $5 \%(\mathrm{w} / \mathrm{v})$ sucrose solution. Floral stems were then placed in a controlled-environment room [20 \pm 2C, $60 \pm 10 \%$ relative humidity $(\mathrm{RH})$ ], $12 \mathrm{~h}$ light (PAR 45 $\left.\mu \mathrm{mol} \cdot \mathrm{m}^{-2} \cdot \mathrm{s}^{-1}\right)$ for evaluation. Leaves on the floral stem were evaluated every other day and leaf blackening was determined as the percentage of total blackened leaf area on a floral stem. When $50 \%$ of the leaf area became black, the vase life of the floral stem was terminated and the days for leaves to reach $50 \%$ of leaf blackening was calculated as postharvest life.

Postharvest flower growth and development. In florescence fresh and dry weights at the commercial harvesting stage (stages 3 and 4) were determined upon arrival from the field and 12 days after harvest in deionized water or 5\% sucrose solution. Dry weight was determined after heating at $80 \mathrm{C}$ for $48 \mathrm{~h}$. The inflorescence diameter was determined every 2 days to 16 days after harvest. The acropetal inflorescence diameter was used to represent the degree of flower opening. Initial results showed that stage 1 flowers never opened after harvest, even when supplied with 5\% sucrose. Therefore, stage 2 flowers were used to measure the continuous increase in inflorescence size postharvest. 
Table 1. Inflorescence bract condition, diameter, and fresh and dry weights at five developmental stages at harvest.

\begin{tabular}{|c|c|c|c|c|}
\hline $\begin{array}{l}\text { Inflorescence } \\
\text { developmental } \\
\text { stage }\end{array}$ & $\begin{array}{c}\text { Bract } \\
\text { condition }\end{array}$ & $\begin{array}{l}\text { Inflorescence } \\
\text { diam } \\
(\mathrm{cm})\end{array}$ & $\begin{array}{c}\text { Fresh } \\
\mathrm{w} \mathrm{t}^{\mathrm{z}} \\
(\mathrm{g})\end{array}$ & $\begin{array}{r}\text { Dry } \\
\text { wt } \\
(\mathrm{g})\end{array}$ \\
\hline$\overline{1}$ & Tightly closed & 3.0 & $71 \mathrm{a}$ & $21 \mathrm{a}$ \\
\hline 2 & Beginning to loosen & 4.0 & $72 \mathrm{a}$ & $24 \mathrm{~b}$ \\
\hline 3 & Starting to separate & 5.0 & $71 \mathbf{a}$ & $25 \mathrm{~b}$ \\
\hline 4 & Open with a cylindrical shape & 6.0 & $71 \mathrm{a}$ & $26 \mathrm{~b}$ \\
\hline 5 & Reflexing outward & 7.0 & $72 \mathrm{a}$ & $26 \mathrm{~b}$ \\
\hline
\end{tabular}

'Data were analyzed by Duncan-Wailer multiple range test, means with the same letter in the same column were not significantly different at $P=0.05, \mathrm{n}=10$.

To determine the relative proportions of the various organs, 20 floral stems at stage 3 or 4 were harvested, trimmed to $45 \mathrm{~cm}$ long with 25 leaves attached, and separated into inflorescence, leaves, and stem to determine fresh weight of each organ. The relative proportion of each organ was calculated as the percentage of the whole floral stem weight.

Inflorescence carbon dioxide evolution rate was determined immediately after harvest and at 3,6, and 9 days after harvest. Floral stems were placed in either deionized water or $5 \%$ sucrose solution under $12 \mathrm{~h}\left(45 \mu \mathrm{mol} \cdot \mathrm{m}^{-2} \cdot \mathrm{s}^{-1} \mathrm{PAR}, 20-22 \mathrm{C}, 60 \%\right.$ to $80 \%$ $\mathrm{RH})$. The inflorescence was sealed in a $600-\mathrm{ml}$ plastic jar for $1 \mathrm{~h}$, a 1-ml sample of the headspace gas was taken, and $\mathrm{CO}_{2}$ content was determined by an infrared gas analyzer and expressed as $\mathrm{ml} \cdot \mathrm{kg}^{-1} \cdot \mathrm{h}^{-1}$.

Nectar production was determined for each developmental stage after arrival from the field. The inflorescence was inserted upside down into a plastic cup and spun in a centrifuge at $200 \times \mathrm{g}$ for $1 \mathrm{~min}$. Nectar was collected from the cup and measured with a graduate cylinder, with the total soluble solids (TSS) determined by refractometry. The floral stems were then placed in deionized water or 5\% sucrose solution at $20-22 \mathrm{C}, 60 \% \pm 10 \% \mathrm{RH}$, and 12 $\mathrm{h}$ light (PAR $45 \mu \mathrm{mol} \cdot \mathrm{m}^{-2} \cdot \mathrm{s}^{-1}$ ) for 7 days to allow sufficient time for nectar production. Nectar was again collected and TSS determined as described above.

Radioactivity labeling and distribution. Individual floral stems at the five stages were trimmed to $45 \mathrm{~cm}$ long with 25 leaves attached and placed into a test tube containing $50 \mathrm{ml}$ deionized water after arrival. The stems were then placed into a fume hood under $12 \mathrm{~h}$ light (PAR $\left.45 \mu \mathrm{mol} \cdot \mathrm{m}^{-2} \cdot \mathrm{s}^{-1}\right)$. A portion $\left(\approx 0.5 \mathrm{~cm}^{2}\right)$ of a leaf in the middle of each floral stem was abraded, and $20 \mu \mathrm{l}$ solution containing $74 \mathrm{kBq}$ of uniformly labeled ${ }^{14} \mathrm{C}$-sucrose (NEC-100, Du Pont Co., NEN Research Products, Boston) was applied. Twenty-four hours later, each floral stem was separated into bracts, florets, receptacle, nectar, and leaves. One gram of each organ or $1 \mathrm{ml}$ of nectar was placed in a scintillation vial containing $1 \mathrm{ml}$ of ScintiGest (Fisher Scientific Company, N. J.) and digested for $48 \mathrm{~h}$ at $22 \mathrm{C}$. Toluene-scintillation liquid ( $10 \mathrm{ml})$ was added to the digested samples and radioactivity determined by a liquid scintillation counter (LS 1801; Beckman Instrument, Calif.). The radioactivity was expressed as disintegrations/rein per $\mathrm{g}$ fresh weight. The radioactivity of individual floral parts and plant organ was calculated to report the percentage of the total radioactivity in the flower stem. The experiment was repeated three times.

Effect of number of leaves on leaf blackening and flower senescence. Leaves of floral stems at stage 3 were removed leaving $5,10,15,20$, and 25 leaves per floral stem after arrival. The floral stems were then placed in deionized water in the controlledenvironment room. Leaf blackening and inflorescence senescence was recorded daily. A typical symptom of inflorescence senescence was the discoloration and curling of the bracts. Therefore a scoring system based on discoloration and curling of the bracts was used to describe the inflorescence senescence: 0 , no discoloration and curling; 1, slight discoloration and curling; 2, moderate discoloration and curling; 3 , severe discoloration and curling; and 4, completely discolored and curled. The percentage leaf blackening and inflorescence senescence seven days after harvest was used for comparison.

Statistical analysis. The experiments were completely randomized design. At least five sterns were used for each treatment and all experiments were repeated at least twice. Treatment results were cross-checked with similar treatments in other experiments. Mean treatment comparisons were made using analysis of variance and the Duncan-Wailer multiple range test and regression analysis was done using the General Linear Model (GLM) procedure (SAS Institute, Cary, N.C.).

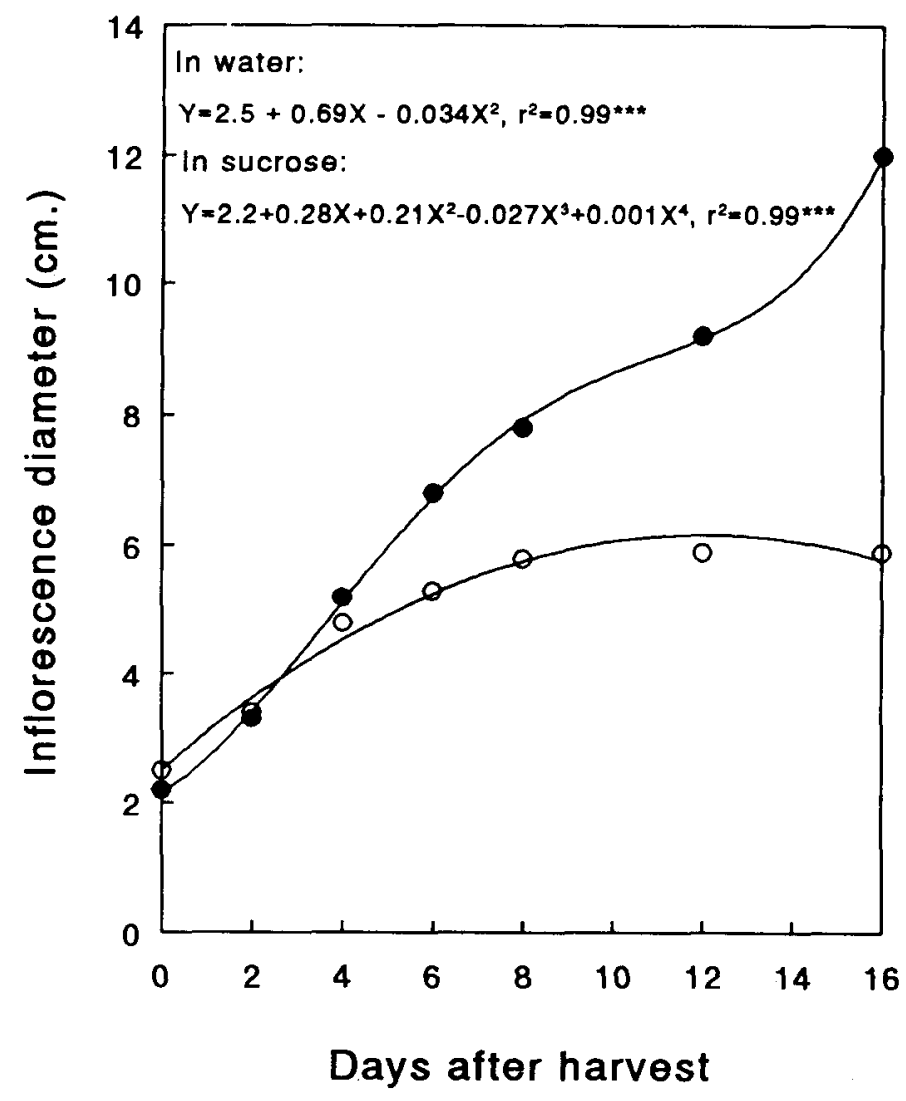

Fig. 1. The change in inflorescence diameter after harvest at stage 2. Floral stems were placed in deionized water (open circles) or $5 \%(\mathrm{w} / \mathrm{v})$ sucrose (solid circles) after harvest at 20-22C, 60\% $\pm 10 \% \mathrm{RH}$, and $12 \mathrm{~h}$ light (PAR $45 \mathrm{mmol}^{-2} \cdot \mathrm{s}^{-1}$ ). Analysis of variance: days after harvest ${ }^{* * *}$, treatment***, days after harvest $\mathrm{x}$ treatment***. Significant at $P=0.001$. 


\section{Results}

Inflorescence growth after harvest. Acropetal in florescence diameter increased from $2.5-5 \mathrm{~cm}$ (4-6 days after harvest) when floral stems were placed in deionized water (Fig. 1 ) and completely stopped 8 days after harvest. The inflorescence diameter of floral stems placed in $5 \%$ sucrose continued to increase to $\approx 8 \mathrm{~cm}, 8$ days after harvest. This represents a 38\% increase over the inflorescence diameter of floral stems placed in deionized water. Maximum inflorescence diameter was reached 15 days after harvest for floral stems placed in sucrose solution (Fig. 1). Inflorescence fresh weight decreased to $\approx 68 \% 12$ days after harvest when placed either in deionized water or $5 \%$ sucrose (Table 2), while dry weight increased $\approx 8 \%$ and $12 \%$ during this period.

Fresh weight distribution and effect of inflorescence development on leaf blackening. A floral stem at stage 3 and 4 with 25 leaves attached averaged $\approx 120 \mathrm{~g}$ fresh weight. The inflorescence was $\approx 66 \%$ of the total fresh weight, stem $18 \%$, and leaves $16 \% 0$ (Table 3). The percentage of leaf blackening of floral stems harvested at different stages and placed in water was significantly higher than those placed in 5\% sucrose solution 7 days after harvest (Fig. 2). In deionized water, leaf blackening varied with stage of flower opening. At stages 1, 3, and 4, flowers had significantly higher percentage of leaf blackening $(88 \%, 90 \%$, and $80 \%$ respectively) than those at stages 2 and 5 (56\% and 60\% respectively). Sucrose at $5 \%$ significantly reduced leaf blackening to $<10 \%$ of the total leaf area at all stages (Fig. 2).

Respiration rate of harvested inflorescence. Respiration rate, as measured by $\mathrm{CO}_{2}$ evolution, varied with stage of flower opening (Fig. 3A). The highest rate of $\mathrm{CO}_{2}$ production was found at stage 1 , followed by stage 3 . The rate of $\mathrm{CO}_{2}$ production at stages 2,4 , and 5 was significantly lower. The carbon dioxide evolution of inflorescences harvested at stage 3 was high 3 days after harvest, then declined 9 days after harvest (Fig. 3B). The postharvest $\mathrm{CO}_{2}$

Table 2. Inflorescence fresh and dry weight at stage 3 measured at the time of harvest and 12 days after harvest. Floral stems were placed in deionized (DI) water or $5 \%$ sucrose solution at $20-22 \mathrm{C}, 60 \% \pm 10 \%$ $\mathrm{RH}, 12 \mathrm{~h}$ light $\left(45 \mu \mathrm{mol} \cdot \mathrm{m}^{-2} \cdot \mathrm{s}^{-1}\right)$.

\begin{tabular}{lcc}
\hline $\begin{array}{l}\text { Days after } \\
\text { harvest }\end{array}$ & $\begin{array}{c}\text { Fresh } \mathrm{wt}^{2} \\
(\mathrm{~g})\end{array}$ & $\begin{array}{c}\text { Dry wt } \\
(\mathrm{g})\end{array}$ \\
\hline 0 & $71.0 \mathrm{a}$ & $25.0 \mathrm{~b}$ \\
12 & & \\
$\quad$ DI water & $55.0 \mathrm{~b}$ & $27.1 \mathrm{a}$ \\
$5 \%$ Sucrose & $54.2 \mathrm{~b}$ & $28.0 \mathrm{a}$
\end{tabular}

'Data were analyzed by Duncan-Wailer multiple range test, means with the same letter in the same column were not significantly different at $P=$ $0.05, \mathrm{n}=10$.

Table 3. Fresh weight distribution of different organs on a floral stem at time of harvest. The floral stems were at stages 3 and 4 with 25 leaves attached.

\begin{tabular}{lcc}
\hline \hline Organ & $\begin{array}{c}\text { Fresh } \\
\mathrm{wt}^{2} \\
(\mathrm{~g})\end{array}$ & $\begin{array}{c}\text { Percentage of } \\
\text { floral stem } \\
(\%)\end{array}$ \\
\hline Whole shoot & $116.75 \pm 16$ & \\
Inflorescence & $77.2 \pm 11$ & $66 \%$ \\
Leaves & $18.1 \pm 5$ & $16 \%$ \\
Stem & $21.4 \pm 4$ & $18 \%$ \\
\hline
\end{tabular}

${ }^{2}$ Data the means of 20 replicates, \pm SD. evolution of inflorescence of stems placed in sucrose solution for 3 days was $15 \%$ higher than that of stems placed in water. It then declined 6 days after harvest, but was still $40 \%$ higher than the control (deionized water). Even 9 days after harvest, the $\mathrm{CO}_{2}$ evolution of sucrose treatment was $60 \%$ higher than the control.

Nectar production. Nectar production was not detected for inflorescence developmental stages 1 to 3 at harvest or 7 days after harvest (Table 4 and 5). Nectar production was detected at stage 4 , averaging $\approx 3 \mathrm{ml}$ per inflorescence, and increased to $\approx 10 \mathrm{ml}$ at stage 5 when flowers frequently became sticky. Total soluble solids in the nectar increased from $15 \%$ at stage 4 to $\approx 24 \%$ at stage 5 (Table 4). Little postharvest nectar production was detected by inflorescences at all stages when floral stems were placed in deionized water for 7 days. Nectar was detected at all opening stages except stage 1 , when floral stems were placed in $5 \% 0$ sucrose solution for 7 days (Table 5). The highest nectar production was found in in florescence harvested at stages 3 and 4 and placed in 5\% sucrose solution. TSS in the nectar of flowers harvested at stage 3 was significantly lower than that of stage 4 for floral stems placed in water or the $5 \%$ sucrose solution (Table 5). The production of nectar declined significantly when flowers were harvested at stage 5 and placed in water or the $5 \%$ sucrose solution. The TSS was highest at stage 5 for floral stems placed in the $5 \%$ sucrose solution.

Radioactivity distribution. The distribution of radioactivity from labeled sucrose applied to a leaf on the floral stem varied with stage of flower opening (Table 6). At stages 1 to 3, little nectar was detected and most of the ${ }^{14} \mathrm{C}$ radioactivity $(90 \%)$ was found in the leaf fraction. The stems contained $5 \%$ of the radioactivity and the percentage declined as the flower opened. The inflorescence parts

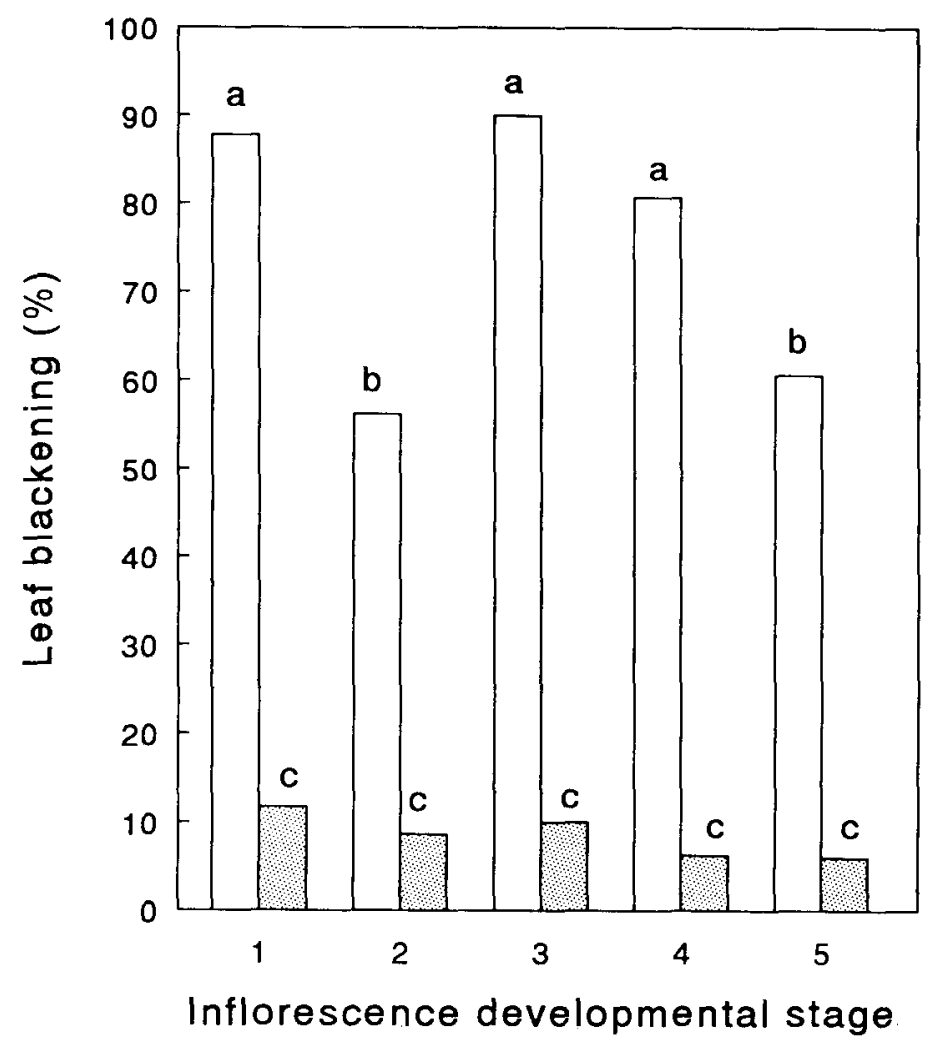

Fig. 2. Percentage leaf blackening of floral stems harvested at different developmental stages, placed in deionized water (open bars) or in $5 \%(\mathrm{w} / \mathrm{v})$ sucrose solution (shaded bars), 7 days after harvest at 20-22C and $12 \mathrm{~h}$ of photosynthetic light (45 $\left.\mu \mathrm{mol}{ }^{-2} \cdot \mathrm{s}^{-1}\right)$. Data analyzed by Duncan-Wailer multiple range test; bars with the same letters were not significantly different at $P=0.05, \mathrm{n}=8$. 
(bracts, florets, and receptacle) contained little radioactivity at all stages. At stage 4, when the in florescence began to produce nectar, the majority of the radioactivity y $(58 \%)$ was detected in the nectar (Table 6). Leaf radioactivity declined at this stage to $39 \%$ of the total. At stage 5, when the inflorescence bracts were fully reflexed,
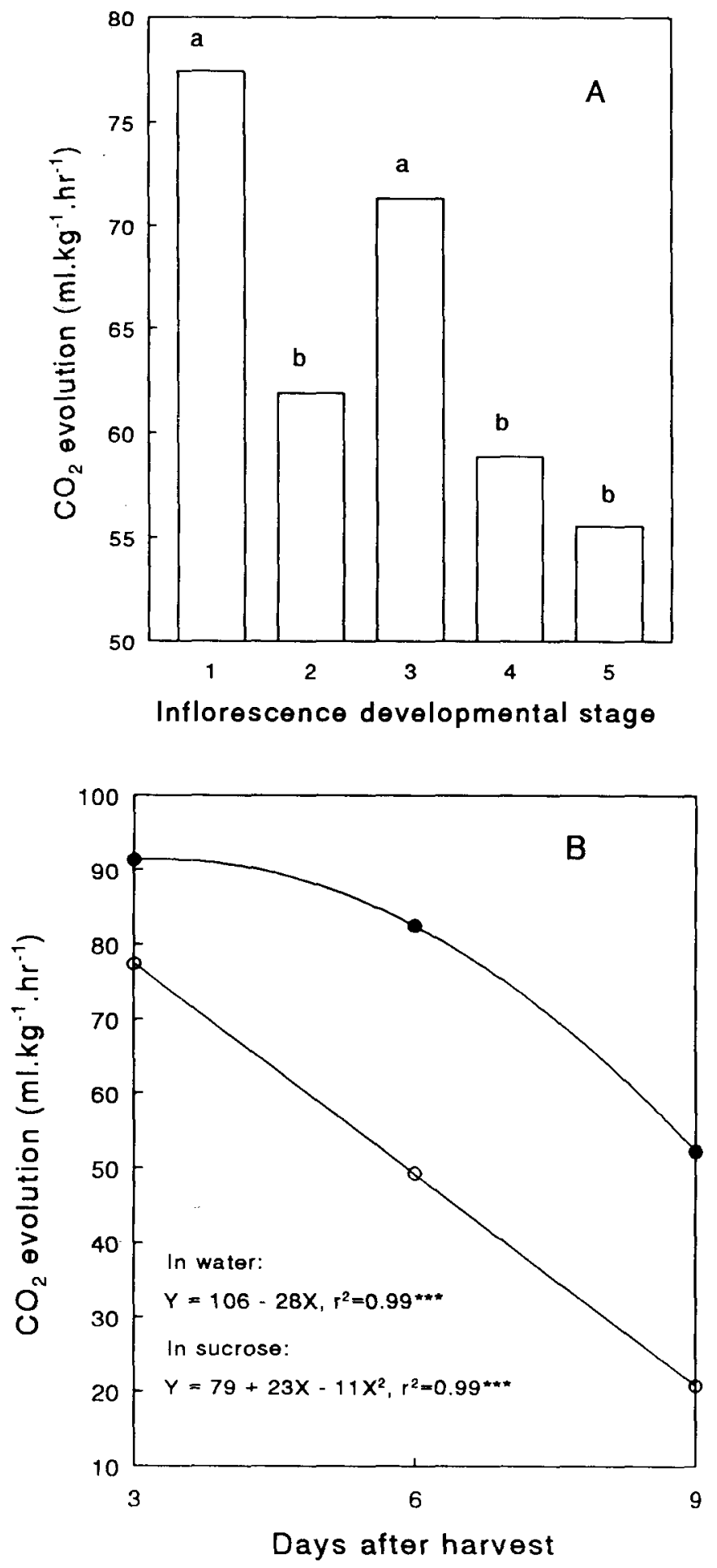

Fig. 3. Carbon dioxide evolution of inflorescence at different developmental stages at harvest (A) and of stage 2 placed in deionized water (open circles) or 5\% sucrose (solid circles) after harvest (B). Data analyzed by Duncan-Wailer multiple range test, bars with same letters were not significantly different at $\mathrm{P}=$ 0.05 with regression analyzed by GLM. Analysis of variance: days after harvest***, treatment ${ }^{* * *}$, days after harvest $\times$ treatment $* * *$. Significant at $P=0.001$. the amount of radioactivity in entire floral stem declined and the nectar contained only $13 \%$ of the radioactivity y. The radioactivity y in nectar fraction continued to decline after stage 5 , while the leaf had up to $97 \%$ of the floral stem total radioactivity (data not shown).

Number of leaves on flower stem and the rate of leaf blackening. The number of leaves on the flower stem significantly $(P<$ 0.05 ) affected the percentage of leaf blackening and flower senescence. The more leaves remaining on the floral stem, the longer the inflorescence vase life and lower percentage leaf blackening (Fig. 4).

\section{Discussion}

The fresh weight of Protea in florescence was two- thirds of the total floral stem's weight. Fresh and dry weights increased slightly during the inflorescence development (Table 1) and dry weight increased slightly after harvest (Table 2). McConchie et al. (1991) found that Protea inflorescence diameter increased from $5 \mathrm{~cm}$ at harvest to $\approx 7 \mathrm{~cm}, 5$ days after harvest of floral stems placed in deionized water, and that $0.5 \%$ sucrose in the vase solution did not promote inflorescence expansion. Our study confirmed their results that inflorescence diameter did increase after harvest when placed in deionized water (Fig. 1), although no further expansion occurred after 8 days. Sucrose at $5 \%$ significantly promoted flower opening until 15 days after harvest (Fig. 1). This suggests that the inflorescence of floral stems placed in water was not able to fully expand due to a lack of carbohydrates. Sucrose at $0.5 \%$ used by McConchie et al. (1991) may not have been sufficient to promote in florescence expansion.

The decline in respiration after harvest (Fig. 3B) was probably due to lack of respiratory substrate when floral stems were placed in water. This behavior is similar to many cut flowers in which the rate of respiration rises to a maximum as the flower start to open, followed by a gradual decline as the flower matures (Halevy and Mayak, 1979). Protea neriifolia is a member of the Protea genus producing 5-6 $\mathrm{ml}$ of nectar per inflorescence with fructose and glucose as the dominant carbohydrates (Cowling and Mitchell, 198 1). In the present study, an average of $9.8 \mathrm{ml}$ nectar per in florescence with a TSS of $23.5 \%$ was found in a mature in florescence. This nectar production requires a carbohydrate supply, and our data suggested that $5.0 \%$ sucrose in the vase solution stimulated nectar production (Table 5). In the absence of sucrose in the vase solution, carbohydrate supply must be met from other sources such as leaves and stem.

Floral stems harvested at all developmental stages and placed in deionized water had $>50 \%$ leaf blackening 7 days after harvest

Table 4. Volume and total soluble solid (TSS) of nectar produced by Protea neriifolia flowers at different developmental stages at harvest ${ }^{2}$.

\begin{tabular}{lcc}
\hline \hline $\begin{array}{l}\text { Developmental stage } \\
\text { of inflorescence }\end{array}$ & \multicolumn{2}{c}{$\begin{array}{c}\text { Nectar } \\
\text { production }\end{array}$} \\
\cline { 2 - 3 } at harvest & Vol (ml) & TSS (\%) \\
\hline 1 & $0 \mathrm{c}$ & $0 \mathrm{c}$ \\
2 & $0 \mathrm{c}$ & $0 \mathrm{c}$ \\
3 & $0 \mathrm{c}$ & $0 \mathrm{c}$ \\
4 & $2.7 \mathrm{~b}$ & $15 \mathrm{~b}$ \\
5 & $9.8 \mathrm{a}$ & $23.5 \mathrm{a}$
\end{tabular}

${ }^{2}$ Values represent average nectar volume $(\mathrm{ml})$ and TSS per inflorescence. ${ }^{y}$ Data analyzed by Duncan-Wailer multiple range test, means with the same letter in the same column were not significantly different at $P=0.05, \mathrm{n}=8$. 
Table 5. The volume and total soluble solids (TSS) of nectar produced by Protea neriifolia inflorescence harvested at different developmental stages 7 days after harvest and placed in deionized water or 5\% sucrose solution, at 20-22C and $12 \mathrm{~h}$ of light PAR $\left.45 \mu \mathrm{mol} \cdot \mathrm{m}^{-2} \cdot \mathrm{s}^{-1}\right)$.

\begin{tabular}{|c|c|c|c|c|}
\hline \multirow{3}{*}{$\begin{array}{l}\text { Developmental } \\
\text { stage of } \\
\text { inflorescence }\end{array}$} & \multicolumn{4}{|c|}{ Nectar production ${ }^{2 y}$} \\
\hline & \multicolumn{2}{|c|}{ Deionized water } & \multicolumn{2}{|c|}{$5 \%$ Sucrose solution } \\
\hline & Vol (ml) & TSS $(\%)$ & Vol (ml) & TSS (\%) \\
\hline 1 & $\mathrm{~N} \mathrm{D}^{\mathrm{x}}$ & ND & $0.0 \mathrm{c}$ & $0.0 \mathrm{c}$ \\
\hline 2 & N D & ND & $1.2 \mathrm{~b}$ & $12.5 \mathrm{~b}$ \\
\hline 3 & $0.05 \mathrm{~b}$ & ND & $3.3 \mathrm{a}$ & $16.3 \mathrm{~b}$ \\
\hline 4 & $0.16 \mathrm{a}$ & 21.7 & $3.9 \mathrm{a}$ & $21.6 \mathrm{a}$ \\
\hline 5 & $0.05 \mathrm{~b}$ & ND & $0.8 \mathrm{bc}$ & $23.7 \mathrm{a}$ \\
\hline
\end{tabular}

${ }^{\overline{2}}$ Values represent average nectar volume $(\mathrm{ml})$ and \% TSS per inflorescence.

'Data analyzed by Duncan-Wailer multiple range test, means with the same letter in the same column were not significantly different at $P=0.05, \mathrm{n}=8$.

'ND = none detected.

Table 6. Redistribution of ${ }^{14} \mathrm{C}$ to different parts of a floral stem at different stages of opening following $24 \mathrm{~h}$ of continuous exposure of ${ }^{14} \mathrm{C}$-sucrose to a floral stem middle leaf.

\begin{tabular}{|c|c|c|c|c|c|}
\hline \multirow[b]{3}{*}{ Section } & \multicolumn{5}{|c|}{ Radioactivity (dmp/g fresh wt) ${ }^{z}$} \\
\hline & \multicolumn{5}{|c|}{ Developmental stages of inflorescence } \\
\hline & 1 & 2 & 3 & 4 & 5 \\
\hline$\overline{\text { Nectar }}$ & 0 & 0 & 0 & 42,164 & 3,265 \\
\hline Stem & 2,498 & 1,682 & 1,997 & 620 & 812 \\
\hline $\mathrm{LL}^{\mathrm{y}}$ & 19,251 & 11,374 & 11,638 & 8,585 & 7,662 \\
\hline ML & 10,540 & 9,847 & 5,588 & 9,961 & 6,377 \\
\hline $\mathrm{HL}$ & 15,894 & 12,430 & 10,579 & 9,628 & 6,303 \\
\hline Bracts & 1,276 & 215 & 384 & 631 & 185 \\
\hline Receptacle & 416 & 572 & 246 & 138 & 297 \\
\hline Florets & 908 & 1,741 & 858 & 1,010 & 534 \\
\hline
\end{tabular}

$\overline{\mathrm{dpm}}=$ Disintegrations per minute. Means, $\mathrm{n}=3$.

${ }^{y} \mathrm{LL}=$ the lowest leaf on the shoot; $\mathrm{ML}=$ the middle leaf on the shoot; $\mathrm{HL}=$ the highest leaf on the shoot.

(Fig. 2). The rate of leaf blackening in stages 1,3 , and 4 was higher than for stages 2 and 5 (Fig. 2). The reason for these difference in leaf blackening rate with different stages was unknown. Since respiration rate was higher at stages 1 and 3 (Fig. 3A) and nectar production started at stage 4 (Table 1), possibly leaf blackening rate would also be higher at those stages. Also, radioactivity was the highest in nectar at stage 4 and declined subsequently (Table 6), hence stages 1,3, and 4 of the in florescence would be expected to have the highest carbohydrate demand. A concentration of 5\% sucrose in the vase solution may provide sufficient carbohydrate for the inflorescence to continue development without inducing carbohydrate stress depletion and thus prevent leaf blackening.

Leaf senescence induced by growth and development of reproductive organs has been observed in many monocarpic crops (Crafts-Brandner and Egli, 1987; Ho et al., 1987; Nooden, 1984). Sink demand for carbohydrates after harvest may deplete carbohydrates in the leaves, leading to a disruption of compartmentation and leaf blackening (McConchie et al., 1991). Sink removal has been found to delay whole plant senescence in many monocapic plants (Ho et al., 1987; Leopold, 1961). Protea inflorescence removal or girdling the inflorescence base has been found to delay leaf blackening (Reid et al., 1989), but the timing of removal might be crucial. McConchie and Lang (1993) found that if the inflorescence is removed after a 24-h shipping interval, significant amount of leaf blackening occurs $(71 \%)$. This implies that 1) timing of removal after harvest influences subsequent blackening and 2) carbohydrate stress leading to significant blackening can occur in a very short time. They also found that leaf starch and sucrose reserves are quickly depleted and that starch concentration of stems dropped to $70 \%$ to $82 \%$ within $24 \mathrm{~h}$ of harvest. These data suggest that leaf blackening may be initiated during shipping. The commercial harvesting stages usually are stages 3 and 4 (Dai, 1993), at which high $\mathrm{CO}_{2}$ production and active nectar production occurs (Fig.3A, Table 4). After harvest, the inflorescence may deplete the carbohydrate very quickly because of nectar production. Radioactivity labeling also showed that $24 \mathrm{~h}$ after harvest, $58 \%$ of radioactivity can be detected in the nectar (Table 6). This indicates that carbohydrate movement from leaf to inflorescence can occur in a very short time, and may lead to leaf blackening during $24 \mathrm{~h}$ of shipping interval. A high sucrose pulse $(20 \%, 24 \mathrm{~h})$ has been used to increase leaf carbohydrate concentrations (Jones, 1991) and significantly reduced $P$. neriifolia postharvest leaf blackening (McConchie and Lang, 1993).

The ability of source leaves to sustain the flower sink demand and hence flower longevity was hypothesized to be determined by the number of leaves on the flower stem. A greater number of leaves having greater ability to respond to the inflorescence sink demand resulted in a slower rate of leaf blackening and inflorescence senescence (Fig. 4). These data indicated the importance of the relationship between leaf carbohydrate source supply and in florescence sink demand. Our data were also consistent with the hypothesis that Protea in florescence was a strong sink for carbohydrate, and this sink demand caused carbohydrate depletion in leaves and thus leaf blackening. Inflorescence expansion, inflorescence respiration, and, most importantly, nectar production are the primary sinks for the carbohydrate depletion. 


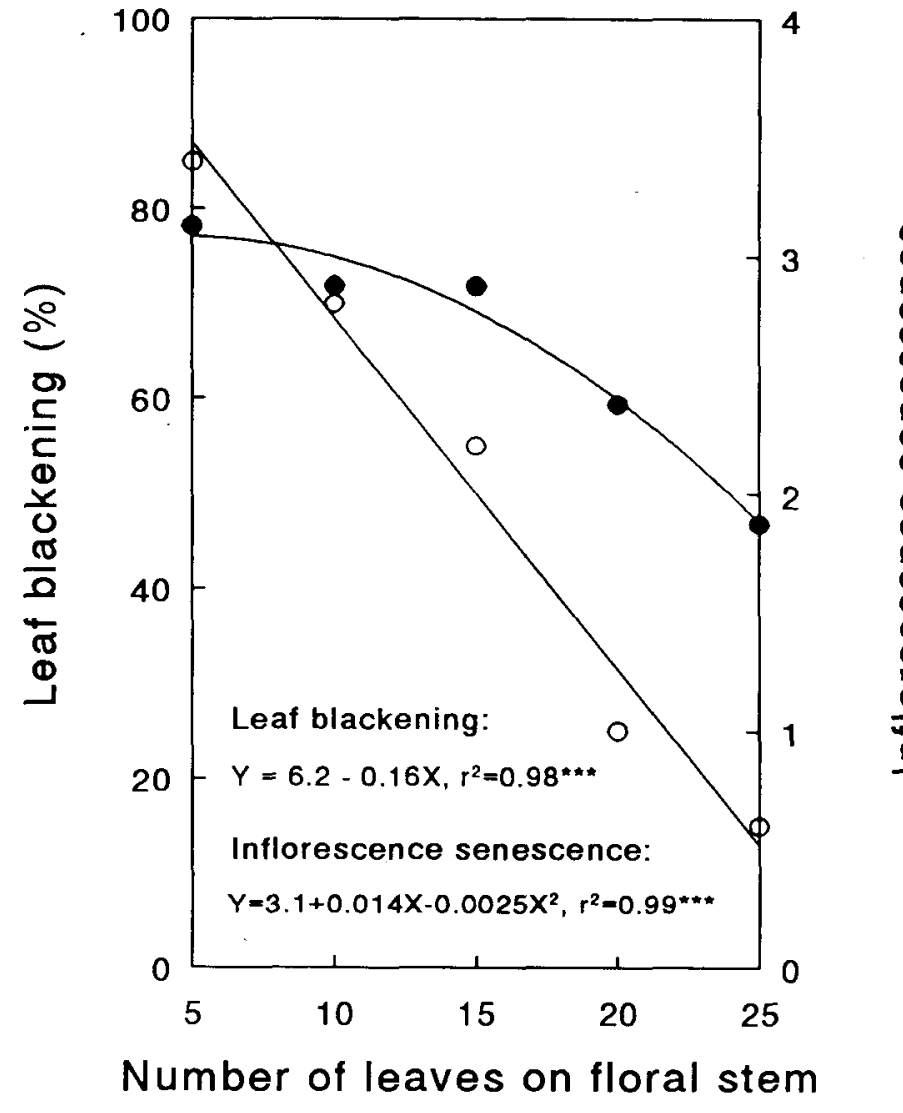

Fig. 4. Effect of number of leaves on a floral stem on leaf blackening (open circles) and flower head senescence (solid circles). Floral stems were placid in deionized water for 7 days after harvest at 20-22C and $12 \mathrm{~h}$ of photosynthetic light (45 umolm $\left.{ }^{-2} \cdot \mathrm{s}^{-1}\right)$. Analysis of variance: number of leaves on leaf blackening ${ }^{* * *}$, on inflorescence senescence". Significant at $P=0.01$ (**) $^{*} 0.001$ (***).

\section{Literature Cited}

Bieleski, R. L., J. Ripperda, J.P. Newman, and M.S. Reid. 1992. Carbohydrate changes and leaf blackening in cut flower stems ofProtea eximia. J. Amer. Soc. Hort. Sci. 177:124-127.

Cowling, R.M. and D.T. Mitchell. 1981. Sugar composition, total nitrogen and accumulation of C-14 assimilates in floral nectaries ofProtea species. J. South African Bot. 47:743-750.

Crafts-Brandner, S.J. and D.B. Egli. 1987. Sink removal and leaf senescence in soybean. Plant Physiol. 85:662-666.

Dai, J.W. 1993. Postharvest leaf blackening inProtea neriifolia $\mathrm{R}$. Br. PhD diss. Univ. of Hawaii at Manoa, Honolulu.

Ferreira, D.I. 1986. The influence of temperature on the respiration rate and browning of Protea neriifolia R. Br. inflorescence. Acta Hort. 185:121129.

Halevy, A.H. and S. Mayak. 1979. Senescence and postharvest physiology of cut flowers, p. 204-236. In: J. Janick (ed.). Horticultural Reviews. vol. 1. AVI Publishing, Westport, Corm.

Ho, 1., F.E. Below, and R.H. Hageman. 1987. Effect of head removal on leaf senescence of sunflower. Plant Physiol. 83:844-848.

Jones, R.B. 1991. Understanding and controlling leaf blackening in Protea leaves: The use of high concentrations of sucrose. Proc. Intl. Protea Assn., 6th Bienn. Conf., 22 to 27 Sept., Perth, W. A., Australia. p. 313-322.

Leopold, A.C. 1961. Senescence\&r plant development. Science 134:17271732.

McConchie, R., N.S. Lang, and K.C. Gross. 1991. Carbohydrate depletion and leaf blackening in Protea neriifolia. J. Amer. Soc. Hort. Sci. 116:10191024

McConchie, R. and N.S. Lang. 1993. Carbohydrate metabolism and possible mechanisms of leaf blackening inProtea neriifolia under dark postharvest conditions. J. Amer. Soc. Hort. Sci. 118:355-361.

Nooden, L.D. 1984. Integration of soybean pod development and monocarpic senescence. Physiol. Plant 62:273-284.

Paull, R.E., T. Goo, R.A. Criley, and P.E. Parvin. 1980. Leaf blackening in cut Protea eximia: The importance of water relations. Acta Hort. 113:139165.

Reid, M. S., W. van Doom, and J.P. Newman. 1989. Leaf blackening in proteas. Acta Hort. 261:81-84.

Rourke, J.P. 1980. The proteas of Southern Africa. Purnell, Capetown. 